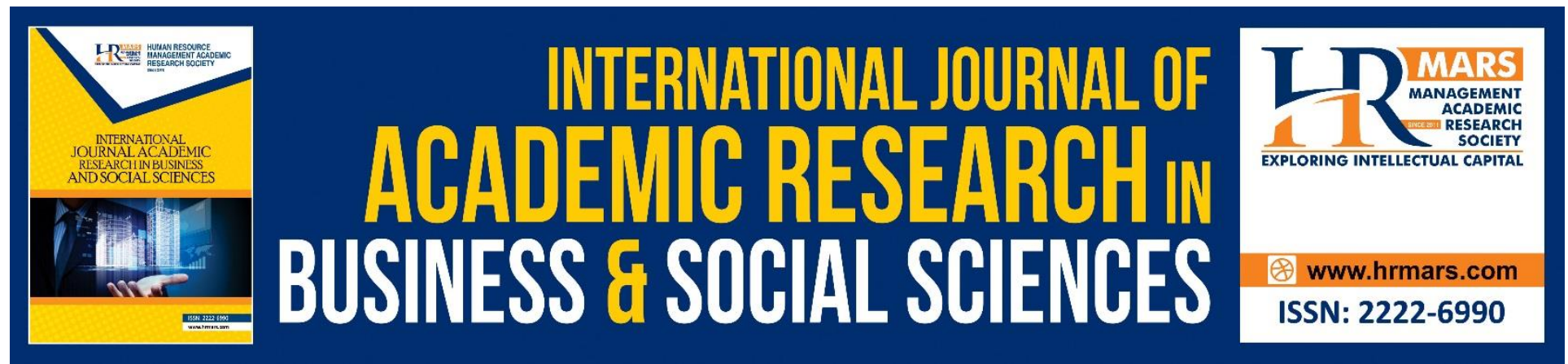

\title{
Kinematic, Physical Fitness and body composition of Heighted and Short Heighted Shot-Put Throwers
}

\author{
Muhammad Zia ul Haq, Usama Maqbool, Hafiz Ali, Maqsood Ahamad, \\ Muhammad Zia ul Haq
}

To Link this Article: http://dx.doi.org/10.6007/IJARBSS/v9-i6/6765

DOI: 10.6007/IJARBSS/v9-i6/6765

Received: 24 April 2019, Revised: 27 May 2019, Accepted: 06 June 2019

Published Online: 28 June 2019

In-Text Citation: (Haq et al., 2019)

To Cite this Article: Haq, M. Z. ul, Maqbool, U., Ali, H., Ahamad, M., \& Haq, M. Z. ul. (2019). Kinematic, Physical Fitness and body composition of Heighted and Short Heighted Shot-Put Throwers. International Journal of Academic Research in Business and Social Sciences, 9(6), 1327-1334.

Copyright: @ 2019 The Author(s)

Published by Human Resource Management Academic Research Society (www.hrmars.com)

This article is published under the Creative Commons Attribution (CC BY 4.0) license. Anyone may reproduce, distribute, translate and create derivative works of this article (for both commercial and non-commercial purposes), subject to full attribution to the original publication and authors. The full terms of this license may be seen at: http://creativecommons.org/licences/by/4.0/legalcode

Vol. 9, No. 6 2019, Pg. 1327 - 1334

http://hrmars.com/index.php/pages/detail/IJARBSS

JOURNAL HOMEPAGE

Full Terms \& Conditions of access and use can be found at http://hrmars.com/index.php/pages/detail/publication-ethics 


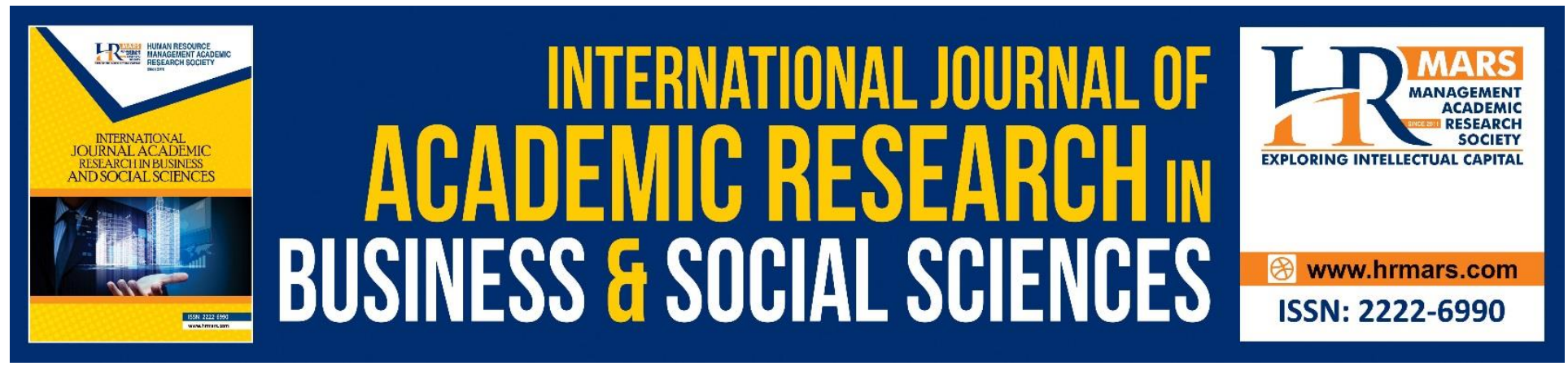

\title{
Kinematic, Physical Fitness and body composition of Heighted and Short Heighted Shot-Put Throwers
}

\author{
Muhammad Zia ul Haq, Usama Maqbool, Hafiz Ali, Maqsood \\ Ahamad
}

Department of Physical Education and Sports Science, The Islamia University of Bahawalpur

\author{
Dr. Muhammad Zia ul Haq \\ Department of Physical Education \& Sports Science, Faculty of Education, the Islamia University \\ of Bahawalpur, Pakistan \\ Email: muhammad.zia@iub.edu.pk
}

\begin{abstract}
The purpose of this study was to compare the kinematics of shot-put throw, physical fitness and of the university shot put players. Twenty subjects were recruited for data collection and divided in two groups by considering their height as group one $(n=08)$ and group two $(n=12)$. Data was collected with a digital video camera, measuring tape for girth, sliding caliper for bone breadth and length and dynamometer for hand grip strength. The physical fitness variables were long standing jump, hand strength, 30-meter dash, flexibility, agility, and throw distance. Independence $t$-test was applied for statistical analysis. The tall heighted throwers were significantly higher, than the short heighted throwers in stature, body mass, vertical jump, distance of the shot-put throw, wrist girth, upper arm length, leg length, arm span, and pelvic breadth. Except the left leg angle all selected variables were not significantly different in the kinematics analysis of the shot-put throw. It is concluded, the tall heighted find biomechanical advantage from their large muscles size and leverage of the longer bone than short height throwers. Therefore, it is proposed selector should also considered the tall throwers for final selection.
\end{abstract}

Keywords: Shot Put, Kinematic, Anthropometric, Videography, Physical Fitness.

\section{Introduction}

The performance of shot-put athletes depends on their anthropometric characteristics, physical fitness and technique. A shot-put thrower desire to maximize the distance of the thrown object. The cover distances of the shot put depends on the height, body mass, angle of release, and 
muscular strength of the athlete. The spin technique involved in complex movement rather than glide technique (Coh \& Jost, 2005). Kinematic analysis shows all parts of movement of the thrower which assist to improve performance. The aspects which influence the performance of shot-put players would be physical strength, body size and techniques. The analysis of the weight, stature, and kinematics of the throw would help to find causes of poor performance and enhance in future (Byun, Fujii, Murakami, Endo, Takesako, Gomi, \& Tauchi, 2008). This the study is the investigation of the kinematics of the shot-put throw, bod composition and physical fitness of the university shot put throwers.

\section{Methodology}

The nature of study was a cross-sectional by using the quantitative method of data collection through videography. Eight heighted players and twelve short height players were selected for this research, through purposive sampling from the Islamia University of Bahawalpur. The selected players were 20-22 years of age, the heighted players were, stature $(180 \pm 0.2 \mathrm{~cm})$, body mass ( $84.10 \pm 7.35)$, and the short heighted players were stature $(154 \pm 0.64)$, body mass (69.56 $\pm 8.06)$. The willing consent was obtained from all participants, and procedure of data collection was briefed to all participants before the commencements of data. The data was collected at the sport gymnasium of the Islamia University of Bahawalpur, Pakistan

\section{Instruments and Procedure of the Anthropometric Measurements}

The anthropometric measures, stature was obtained with stadiometer in $\mathrm{cm}$. Weight was recorded with digital weight balance in $\mathrm{kg}$. A harpenden skinfold caliper to measure the skinfolds in millimeter. The skinfolds were triceps, subscapular, biceps, illiaccrest, supraspinale, abdomen, thigh, and calf. Girths with metallic 1-meter tape as arm relax, arm flex, forearm, chest, waist, hips, thigh, and calf. A bone caliper applied to assess the lengths of arm, leg, breadths of shoulders, pelvis, chest, elbow and knee. A wooden box was used to examine the sitting height. A horizontal scale was pasted on the wall to assess the arm span. The guide line of the International Kinanthropometric Society (ISAK) was followed during the anthropometric assessments.

\section{Physical Fitness Tests}

Speed was assessed by recording the time of 30-meter dash run. The time was recorded from the instigation of movement from the starting point to the finish line. The $10 \times 5-\mathrm{m}$ shuttle run was recorded by using $5 \times 10-\mathrm{m}$ shuttle sprint in the following of the previous study (Nakata, Nagami, Higuchi, Sakamoto, \& Kanosue, 2013). An agility test was determined by the specific zig zag run of a subject such as three lines were marked with 5 meters. Agility times were recorded by using a digital stopwatch. The timer began as an athlete initiate his movement and stopped as crossed the finish line.

The standing long jump, the subjects were in standing position behind the starting line and jump forward as far as possible. The distance from the starting line to the heel of the closest foot was recorded, measurements was recorded in centimeter (Kohmura et al., 2008). The flexibility was judged through sit and reach. The participant had to sit on the floor without shoes, 
and extend his knees. The both hands on the device for pushing with the tip of the fingers with both hands, and maximum reached point was considered as the final score. The subjects were in sat position for sit-ups on the floor, and hands crossed at the chest, move forward to touch his elbows with knees, and return back again to initial position and total within 30 seconds was recorded as final score. The hand grip strength was recorded with digital dynamometers (Koley et al., 2012), and data was interpreted in kilogram. The dynamometer is calibrated, body position for hand grip strength were in upstanding, with flexion of elbow at ninety degrees (Koley \& Yadev, 2009), and subject was remained neutral while applied force (Koley et al., 2012).

\section{Video Analysis of the Shot Put}

A digital video camera, was operated at 30/ frames per second for recording the shot-put action of the throwers. The Kinovea software was used for kinematics analysis. Six throws were recorded of each participant for further kinematics analysis. One-meter calibration frame was placed in between the performing area and video camera for linear kinematics. The selected variables of kinematics were stride length, knee angle, hip angle, trunk angle, shoulder angle, elbow and wrist angle and height of release. The stride length was defined as linear distance from the toe of left foot to the toe of right foot. The angular position was considered as $180^{\circ}$ for the vertical position of the joint and zero ${ }^{\circ}$ for full bending of the joint (Inkster, Murphy, Bower, \& Watsford, 2010). Ankle angle was considered as the connection of toe-to-ankle, and knee to ankle, knee angle from ankle to knee and hip to knee, hip angle from knee to hip and shoulder to hip, shoulder angle from hip to shoulder and from elbow to shoulder, the elbow angle from shoulder to elbow and wrist to elbow. The height was described from the toe to the put and hand contact.

\section{Statistical Analysis}

Mean and Standard Deviation of all variables were reported, and Independence $t$-test was applied to examine difference among two groups in the anthropometric and physical fitness and kinematics of shot put. The $\alpha$ value adjusted at $P<0.05$ for all variables.

\section{Result}

Table 1 shows significant difference in stature (heighted throwers $=182.88 \pm 4.65$; short heighted $=154.84 \pm 0.64 ; t=85.59, P=.04$ ), and body mass (heighted throwers $=84.00 \pm 7.34$; short heighted $=69.69 \pm 8.06: t=3.22, P=.01$ ).

Table 1: Descriptive measure of university shot put male players

\begin{tabular}{|c|c|c|c|c|c|}
\hline Variables & & Mean & Std. D & $t$. & Sig. \\
\hline \multirow[t]{2}{*}{ Age(years) } & Heighted & 23.25 & 0.5 & 0.451 & 0.66 \\
\hline & Shorter & 22.94 & 1.34 & & \\
\hline \multirow[t]{2}{*}{ Stature $(\mathrm{cm})$} & Heighted & 182.88 & 4.65 & 85.59 & 0.04 \\
\hline & Shorter & 154.84 & 0.64 & & \\
\hline \multirow[t]{2}{*}{ Body mass (Kg) } & Heighted & 84.10 & 7.35 & 3.22 & 0.01 \\
\hline & Shorter & 69.69 & 8.06 & & \\
\hline
\end{tabular}

Significant value $P<0.05$ 
Table 2 shows significant difference in in bench press (heighted throwers $=32.52 \pm 6.57$; shorter $=25.63 ; t=2.06, P<.04$. vertical jump (heighted throwers $44.75 \pm 6.60$; shorter $=36.45 \pm 7.26$; $t=2.06, P<.05$. Throw distance (heighted throwers $=7.98 \pm 0.12$; shorter $=5.99 \pm 1.06 ; t=3.69$, $P=.00$.

Table 2: Descriptive physical fitness of university shot put male players

\begin{tabular}{|c|c|c|c|c|c|}
\hline Variables & Groups & Mean & Std. D & $t$ & Sig. \\
\hline \multirow{2}{*}{ Hand Grip strength (Kg) } & Heighted & 83.5 & 14.36 & 1.32 & 0.20 \\
\hline & Shorter & 70.19 & 18.7 & & \\
\hline \multirow{2}{*}{ Standing broad jump (feet) } & Heighted & 6.78 & 0.93 & 0.73 & 0.48 \\
\hline & Shorter & 6.54 & 0.49 & & \\
\hline \multirow{2}{*}{ Sit-ups in one minute (sec) } & Heighted & 20.53 & 7.14 & -1.19 & 0.25 \\
\hline & Shorter & 24.14 & 5.05 & & \\
\hline \multirow{2}{*}{ one bench press $\max (\mathrm{kg})$} & Heighted & 32.52 & 6.57 & 2.77 & 0.04 \\
\hline & Shorter & 25.63 & 4.29 & & \\
\hline \multirow{2}{*}{ one squat max (kg) } & Heighted & 30.20 & 11.55 & 1.31 & 0.21 \\
\hline & Shorter & 22.5 & 10 & & \\
\hline \multirow{2}{*}{ Race $30 \mathrm{~m}$ (sec) } & Heighted & 6.18 & 1.89 & 0.77 & 0.45 \\
\hline & Shorter & 5.7 & 0.89 & & \\
\hline \multirow{2}{*}{ Flexibility (inch) } & Heighted & 9.75 & 3.3 & 0.16 & 0.87 \\
\hline & Shorter & 9.5 & 2.6 & & \\
\hline \multirow{2}{*}{ Agility (sec) } & Heighted & 11.62 & 1.07 & 0.33 & 0.74 \\
\hline & Shorter & 11.49 & 0.57 & & \\
\hline \multirow{2}{*}{ Vertical Jump (cm) } & Heighted & 44.75 & 6.6 & 2.06 & 0.05 \\
\hline & Shorter & 36.45 & 7.26 & & \\
\hline \multirow{2}{*}{ Balance (Sec) } & Heighted & 68.78 & 29.56 & 1.51 & 0.15 \\
\hline & Shorter & 52.76 & 16.1 & & \\
\hline \multirow{2}{*}{ Throw Distance (m) } & Heighted & 7.98 & 0.12 & 3.69 & 0.00 \\
\hline & Shorter & 5.99 & 1.06 & & \\
\hline
\end{tabular}

Significant value $P<0.05$

Table 3 shows significant difference in the scores for pelvic breadth (heighted thrower $=34.01 \pm$ 2.14; short heighted $=30.32 \pm 3.16: \mathrm{t}=2.19, \mathrm{P}=.04$ ). Wrist girth (heighted throwers $=18.26 \pm$ 0.49 ; short heighted $=16.58 \pm 0.81: t=3.94, \mathrm{P}=.00$. Arm length (heighted thrower $=36.00 \pm$ 2.45; short heighted $=31.88 \pm 1.59: \mathrm{t}=4.19, \mathrm{P}=.00$. Leg length (heighted throwers $=96.51 \pm 3.10$; short heighted $=88.51 \pm 3.87 ; \mathrm{t}=3.814, \mathrm{P}=.00$. Arm span (heighted throwers $=185.00 \pm 0.82$; Short heighted $=157.13 \pm 1.63 ; \mathrm{t}=32.741, \mathrm{P}=.000$. 
Table 3: Descriptive Anthropometric Measurement of University Shot Put Male Players

\begin{tabular}{|c|c|c|c|c|c|}
\hline Variables & Groups & Mean & Std. D & $t$ & Sig. \\
\hline \multirow{2}{*}{ Arm flex girth $(\mathrm{cm})$} & Heighted & 30.26 & 2.04 & 1.34 & 0.20 \\
\hline & Shorter & 25.70 & 6.62 & & \\
\hline \multirow{2}{*}{ Arm relax girth $(\mathrm{cm})$} & Heighted & 26.26 & 1.89 & 1.35 & 0.19 \\
\hline & Shorter & 23.39 & 4.08 & & \\
\hline \multirow{2}{*}{ Forearm girth $(\mathrm{cm})$} & Heighted & 24.56 & 2.34 & 1.84 & 0.08 \\
\hline & Shorter & 22.25 & 3.33 & & \\
\hline \multirow{2}{*}{ Chest girth $(\mathrm{cm})$} & Heighted & 95.5 & 4.04 & 1.40 & 0.18 \\
\hline & Shorter & 85.32 & 14.12 & & \\
\hline \multirow{2}{*}{ Thigh girth $(\mathrm{cm})$} & Heighted & 51.26 & 2.97 & 1.13 & 0.27 \\
\hline & Shorter & 47.94 & 5.62 & & \\
\hline \multirow{2}{*}{ Calf girth $(\mathrm{cm})$} & Heighted & 35.51 & 1.72 & 1.45 & 0.17 \\
\hline & Shorter & 33.39 & 2.77 & & \\
\hline \multirow{2}{*}{ Wrist girth $(\mathrm{cm})$} & Heighted & 18.26 & 0.49 & 3.94 & 0.00 \\
\hline & Shorter & 16.58 & 0.81 & & \\
\hline \multirow{2}{*}{ Shoulder breadths (m) } & Heighted & 13.28 & 2.18 & 1.72 & 0.10 \\
\hline & Shorter & 11.65 & 1.59 & & \\
\hline \multirow{2}{*}{ Pelvic Breath $(\mathrm{cm})$} & Heighted & 34.01 & 2.15 & 2.19 & 0.04 \\
\hline & Shorter & 30.32 & 3.16 & & \\
\hline \multirow{2}{*}{ Upper arm length (cm) } & Heighted & 36.00 & 2.45 & 4.19 & 0.00 \\
\hline & Shorter & 31.88 & 1.58 & & \\
\hline \multirow{2}{*}{ Lower arm length $(\mathrm{cm})$} & Heighted & 28.53 & 1.73 & 1.40 & 0.18 \\
\hline & Shorter & 27.14 & 1.74 & & \\
\hline \multirow{2}{*}{ Hand length $(\mathrm{cm})$} & Heighted & 19.25 & 0.5 & 1.75 & 0.10 \\
\hline & Heighted & 16.8 & 2.74 & & \\
\hline \multirow{3}{*}{ Leg length $(\mathrm{cm})$} & Shorter & 96.51 & 3.1 & 3.81 & 0.00 \\
\hline & Heighted & 88.51 & 3.87 & & \\
\hline & Shorter & 185.15 & 0.82 & 32.74 & 0.00 \\
\hline Arm span $(\mathrm{cm})$ & Heighted & 157.13 & 1.63 & & \\
\hline
\end{tabular}

Significant value $P<0.05$

The left knee $^{0}$ at release (heighted $=162.75 \pm 16.32$; short heighted $=146 \pm 10.65 ; t=1.829, P=$ .04 . 
Table 4: Descriptive angular kinematic of university shot put male players

\begin{tabular}{|c|c|c|c|c|c|}
\hline Variables & Groups & Mean & Std. D & $t$ & Sig. \\
\hline \multirow{2}{*}{ Right elbow at Preparatory } & Heighted & 28.5 & 9.11 & -0.64 & 0.53 \\
\hline & Shorter & 31.63 & 8.72 & & \\
\hline \multirow{2}{*}{ Left elbow at Preparatory } & Heighted & 124.5 & 9.82 & -1.71 & 0.11 \\
\hline & Shorter & 141.69 & 19.23 & & \\
\hline \multirow{2}{*}{ Right knee at Preparatory } & Heighted & 131.75 & 14.43 & -0.11 & 0.91 \\
\hline & Shorter & 132.81 & 17.27 & & \\
\hline \multirow{2}{*}{ Left knee at Preparatory } & Heighted & 128.25 & 32.57 & 0.38 & 0.38 \\
\hline & Shorter & 122.69 & 24.68 & & \\
\hline \multirow{2}{*}{ Stride length Preparatory } & Heighted & 0.37 & 0.08 & -0.19 & 0.85 \\
\hline & Shorter & 0.38 & 0.11 & & \\
\hline \multirow{2}{*}{ Trunk angle at Preparatory } & Heighted & 198.25 & 16.91 & 0.28 & 0.78 \\
\hline & Shorter & 193.69 & 30.81 & & \\
\hline \multirow{2}{*}{ Right elbow at release } & Heighted & 124.12 & 67.83 & 0.87 & 0.40 \\
\hline & Shorter & 94.94 & 58.11 & & \\
\hline \multirow{2}{*}{ Left elbow at release } & Heighted & 111.75 & 11.18 & -1.18 & 0.25 \\
\hline & Shorter & 127.56 & 25.82 & & \\
\hline \multirow{2}{*}{ Right Knee at release } & Heighted & 148.10 & 11.2 & -0.05 & 0.96 \\
\hline & Shorter & 148.5 & 17.34 & & \\
\hline \multirow{2}{*}{ Left knee at release } & Heighted & 162.75 & 16.32 & 1.83 & 0.04 \\
\hline & Shorter & 146.63 & 10.65 & & \\
\hline \multirow{2}{*}{ Stride length at release } & Heighted & 0.59 & 0.14 & -0.01 & 0.99 \\
\hline & Shorter & 0.59 & 0.1 & & \\
\hline \multirow{2}{*}{ Trunk at release } & Heighted & 194 & 16.87 & 0.89 & 0.39 \\
\hline & Shorter & 183.19 & 22.71 & & \\
\hline
\end{tabular}

Significant value $P<0.05$

\section{Discussion and Conclusion}

Eight heighted and 12 short heighted players were purposively selected for this study. Result shows the significant different in the selected variables as stature, body mass, wrist girth, pelvises girth, upper arm length, leg length, arm span, bench press, standing long jump and throwing distance. On the other hand, in the kinematic analysis except left knee angle all kinematics were not significantly different among heighted and short heighted throwers. It shows that height contribute to the playing ability of shot-put throwers. Liu ang Wang (2000) also use these variables of Kinematic analysis body mass, jump and throw distance in two groups' $=3.69, \mathrm{P}=.00$ because low release angle, insufficient leg strength, slower movement time, low push off force from the ground. Further, the pelvic girth, wrist girth, upper arm length, total leg length and arm span were significant difference. 
The shot-put performance mostly depends on the athlete's ability with the combination of throwing velocity, angle of throw, and height of release distance. This study confirms the finding of (Aleksic-Veljkovic, Puletic, Rakovic, Stankovic, Bubanj, \& Stankovic, 2011). It is necessary to correct the technique of throwers through training for higher achievements. The finding of this is useful for coaches and athletes, which assists them for further improvement in their shot put techniques.

\section{References}

Aleksic-Veljkovic, A., Puletic, M., Rakovic, A., Stankovic, R., Bubanj, S., \& Stankovic, D. (2011). Comparative kinematic analysis of release of the best Serbian shot putters. Factauniversities-series: Physical Education and Sport, 9(4), 359-364.

Byun, K. O., Fujii, H., Murakami, M., Endo, K., Takesako, H., Gomi, K., \&Tauchi, K. (2008). A biomechanicalanalysis of the men's shot put at the 2007 World Championships in Athletics. New Studies in Athletics, 2, 53-62.

Coh, M., Stuhec, S., \& Supej, M. (2008). Comparative biomechanical analysis of the rotational shot-put technique. Collegium antropologicum, 32(1), 249-256.

Inkster, B., Murphy, A., Bower, R., \& Watsford, M. (2010). Differences in the kinematics of the baseball swing between hitters of varying skill. Journal of Science and Medicine in Sport, 12, 1050-1054. DOI: 10.1249/MSS.0b013e318203626a.

Kohmura, Y., Aoki, K., Yoshigi, H., Sakuraba, K., \& Yanagiya, T. (2008). Development of a baseballspecific battery of tests and a testing protocol for college baseball players. The Journal of Strength \& Conditioning Research, 22(4), 1051-1058.

Koley, S., \& Yadav, K. M. (2009). An association of hand grip strength with some anthropometric variables in Indian cricket players. Facta universitatis-series: Physical Education and Sport, $7(2), 113-123$.

Koley, S., Kumaar, B. S., \& Shadagopan, S. P. (2012). Anthropometric physical strength, body composition and performance test profiles of inter-district level male cricketers of punjab, india. Anthropologist, 14(5), 445-451.

Liu, W., \& Wang, M. (2000). Kinematic analysis of shot put in elite athletes-a case study. In ISBSConference Proceedings Archive.

Nakata, H., Nagami, T., Higuchi, T., Sakamoto, K., \& Kanosue, K. (2013). Relationship between performance variables and baseball ability in youth baseball players. The Journal of Strength \& Conditioning Research, 27(10), 2887-2897. 
INTERNATIONAL JOURNAL OF ACADEMIC RESEARCH IN BUSINESS AND SOCIAL SCIENCES

Vol. 9, No. 6, June, 2019, E-ISSN: 2222-6990 @ 2019 HRMARS 